\title{
An empirical study of managers' usage intention in BI
}

\author{
Yu-Wei Chang $\cdot$ Ping-Yu Hsu $\cdot$ Wen-Lung Shiau
}

Received: 15 December 2012/Accepted: 27 March 2013/Published online: 17 April 2013

(C) The Author(s) 2013. This article is published with open access at Springerlink.com

\begin{abstract}
In a changing business environment, data within and around organizations rapidly accumulate. In recent years, many organizations have implemented business intelligence (BI) to manage and refine the vast stocks of data. The effective use of BI can support managers to make faster and better decisions. The goal of this study is to investigate how to increase a manager's intention to read information and to create reports. Based on the technology acceptance model, a research model is developed and tested to assess the factors (i.e., usefulness and ease of use) affecting a manager's intention to use BI. In addition, the relationship between the intention to read information and the intention to create reports is linked using Dholakia and Bagozzi (D\&B) model. A survey of 271 managers supports the proposed model. The empirical results show that the usefulness of BI directly and indirectly affects the intention to read information. Both the reading and creating interfaces of BI affect the intention to read information and the intention to create reports, respectively. The intention to read information positively and significantly affects the intention to create reports. Given the empirical findings, this study provides theoretical and managerial insights for organizations and managers.
\end{abstract}

\section{Y.-W. Chang · P.-Y. Hsu ( $\square)$}

Department of Business Administration, National Central

University, No.300, Jhongda Rd., Jhongli City,

Taoyuan County, Taiwan

e-mail: pyhsu@mgt.ncu.edu.tw

W.-L. Shiau

Department of Information Management, Ming Chuan

University, No.5, De Ming Rd., Gui Shan District,

Taoyuan County, Taiwan
Keywords Business intelligence - Decision making · Technology acceptance model $\cdot$ D\&B model · Behavioral intention

\section{Introduction}

Using electronic devices, computers, and networks, humans create 2.5 quintillion bytes of data daily (IBM 2012). They grew from 161 exabytes in 2006 to 988 exabytes in 2010. In 2011, 1.8 zetabytes of information was created and replicated (Gantz et al. 2008). Data help organizations understand their business, improve performance, and build stronger relationships with employees, customers, and partners (SAP AG 2008). In recent years, many organizations have implemented business intelligence (BI) to manage and refine the vast stocks of data (Hong et al. 2006; Watson et al. 2001). The software revenue from BI platforms was estimated to be 12.2 billion in 2011 (Gartner 2012).

BI is both a process and a product (Jourdan et al. 2008). From the perspective of a process, BI aims to increase the decision-making quality and to reduce the time it takes (Pirttimäki and Hannula 2003). It encompasses complete data warehousing process, including data extraction, transformation, and loading (ETL). On the other hand, from the perspective of a product, BI is a family of products that support business users' decision-making processes-from quickly access to business information to easily create reports. It provides powerful tools to perform query, report, and multidimensional analysis. Thus, BI provides friendly interfaces for supporting business users to read information and to create reports (Inmon 2005).

Reading information means that users access data on detail or summary levels within business environments. 
They can read key performance indicators in a variety of formats, including reports, charts, and dashboards. On the other hand, creating reports means that users author personalized information without the need of coding on wellorganized data formats, such as cubes and operational data stores. They can create their own reporting environments and analyze ad-hoc data (SAP AG 2008).

To make effective use of $\mathrm{BI}$, organizations must understand how to increase managers' intention to read information and to create reports. The technology acceptance model (TAM) posits that the behavioral intention is determined by perceived usefulness (PU) and perceived ease of use (PEOU) (Davis 1986, 1989). If a user believes that using a particular system would enhance his/her job performance or free of effort, he/she will have high willingness to use the system. PEOU also has a positive effect on PU. The TAM has been widely applied in a variety of decision support tools, such as data warehouse, decision support systems (DSS), and executive information systems (EIS) (Chan 2009; Devaraj et al. 2008; Djamasbi et al. 2010; Elbeltagi et al. 2005; Hart and Porter 2004; Hong et al. 2006; Pijpers et al. 2001).

To the best of our knowledge, there is only one literature of human-computer interaction (HCI) on BI usage. That is, six design guidelines are proposed to improve user acceptance of system (Mayer et al. 2011). Even extending the scope of literature review to HCI of decision support systems (Djamasbi and Loiacono 2008; Rathnam and Mannino 1995; Sankar et al. 1995; Speier and Morris 2003), only limited numbers of studies have been found. Among them, scholars propose guidelines and models to develop user interfaces for DSS (Rathnam and Mannino 1995; Sankar et al. 1995). Djamasbi and Loiacono (2008) also focus on the influence of the display interface design on decision-making performance. None of these studies have investigated the influence of user perception of the interface on usage intention.

Given that BI is useful and easy to use for business users, it is reasonable to expect that managers should have high intention to read information and to create reports. However, SAP reports that most managers only read information from reports, whereas only $10 \%$ of managers create their own ad-hoc reports and $30 \%$ of them perform deep analysis (SAP AG 2008). According to TAM-related studies, system usage intention is measured as a single construct, which does not distinguish the intentions between reading and creation. The results cannot explain the phenomena that business users are willing to read information from reports but have low intention to create reports. Thus, the intention to use BI should be split into intention to read information and intention to create reports. In addition, the interfaces for reading information and creating reports are different for most BI. PEOU is therefore divided into two parts: perceived ease of use to read (PEOUR) and perceived ease of use to create (PEOUC).

Furthermore, Dholakia and Bagozzi (D\&B) model (2002) is extended to investigate the relationship between intention to read information and intention to create reports. The D\&B model postulates that the implementation intention is influenced by the goal intention. That is, if an individual has a strong intention to attain a goal, he/she will have a strong intention to perform an action for goal attainment. Since creating reports is one of the possible ways to access information, managers who intend to read information may be willing to create their own reports. Therefore, to the best of our knowledge, this study is the first to distinguish usage intention into two different constructs while linking them with the $\mathrm{D} \& \mathrm{~B}$ model to investigate the effects of user perceptions.

Given the above discussion, we will address three research questions:

1. Do PU and PEOUR affect intention to read information?

2. Do PU and PEOUC affect intention to create reports?

3. Does intention to read information affect intention to create reports?

The empirical results show that the traditional TAM cannot explain the relationship between user perceptions of system and intention to create reports while the antecedents of intention to read information are in line with the TAM. PEOUC does not significantly affect PU of BI and PU does not significantly affect intention to create reports. In addition, intention to read information indeed leads to intention to create reports.

The remainder of this paper is organized as follows. Section 2 reviews the relevant literature and theories. Section 3 describes the proposed research model and hypotheses. Section 4 details the research methodology and data collection. Section 5 presents the results from the model analysis. Section 6 presents the findings based on the results. Section 7 provides the theoretical and practical implications of this study. Finally, Sect. 8 offers a conclusion and limitations.

\section{Literature review}

\subsection{Technology acceptance model}

The technology acceptance model (TAM) is based on the theory of reasoned action (TRA) (Fishbein and Ajzen 1975). The TRA explains and predicts an individual's performance in a specific behavior in organizations. In addition, Fishbein and Ajzen (1975) posit that an 
individual's behavioral intention is determined by his/her subjective norm and attitude toward behavior. Subjective norm is defined as "an individual's perception of whether people important to the individual think the behavior should be performed." Attitude toward behavior is defined as "an individual's positive or negative feelings about performing a behavior."

According to the TRA, Davis (1986) develops the TAM to explain and predict user acceptance of IS or IT. In the TAM, perceived usefulness (PU) and perceived ease of use (PEOU) are positively associated with the behavioral intention. PEOU is also positively associated with PU (see Fig. 1). PU is defined as that "an individual believes that using a particular system would enhance his/her job performance." PEOU is defined as that "an individual believes that using a particular system would be free of effort" (Davis 1989).

Subsequent research has employed the TAM to explain the use of a variety of IS, such as DSS (Devaraj et al. 2008; Djamasbi et al. 2010; Hong et al. 2006; Pommeranz et al. 2011), enterprise resource planning systems (AmoakoGyampah and Salam 2004; Amoako-Gyampah 2007; Bueno and Salmeron 2008; Scott and Walczak 2009), knowledge management systems (Hester 2011; Kuo and Lee 2011), e-commerce (Chong et al. 2012; Gefen et al. 2003; Vijayasarathy 2004; Zarmpou et al. 2012), and web services (Hsu and Lin 2008; Lederer et al. 2000; Moon and Kim 2001; Schilke and Wirtz 2012).

The above-mentioned studies have conceptualized system usage intention as a single construct and have neglected other use behaviors (Benbasat and Barki 2007). However, BI provides friendly interfaces for supporting business users to read information and to create reports (Inmon 2005). Thus, the intention to use BI should be split into the intention to read information and the intention to create reports. In the next section, we discuss the effects of PU and PEOU on the two different intentions.

\subsection{Dholakia and Bagozzi model}

The Dholakia and Bagozzi (D\&B) model (2002) is based on the model of action phase (MAP). The MAP addresses the conceptual separation between goal-setting and goalstriving processes (Gollwitzer 1996; Heckhausen and Kuhl 1985). The goal-setting process is separated into pre- and

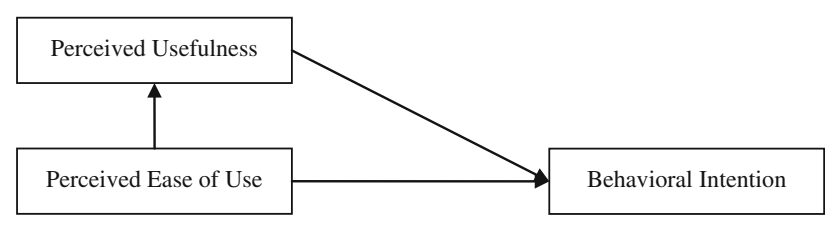

Fig. 1 Technology acceptance model (Venkatesh and Davis 2000) post-decisional phases. In the pre-decisional phase, an individual engages in information search, acquisition, and use of different choice strategies. In the post-decisional phase (i.e., pre-actional phase), an individual decides on a plan of action to attain the chosen goal. The goal-striving process is separated into action and post-actional phases. In the action phase, an individual engages in progress toward goal attainment. In the post-actional phase, an individual examines whether the attained outcomes are consistent with the chosen goal.

Based on the MAP, Dholakia and Bagozzi (2002) propose the D\&B model to explain the processes from the goal to the implementation. The pre-decisional phase forms the "goal intention," whereas the post-decisional phase is the same as the "implementation intention" (Dholakia and Bagozzi 2002; Perugini and Conner 2000). The goal intention means that an individual has chosen a goal and is committed to attain it. The implementation intention means that an individual has chosen an action for goal attainment (Bagozzi et al. 2003). Therefore, the goal intention precedes the implementation intention (see Fig. 2).

The process can be applied to select a university to attend, to donate blood, to get flu shots, to achieve a desired body weight, etc. (Beach 1990; Dholakia et al. 2007; Svenson 1997; Yates 1990). In the case of the weight loss, the goal intention is expressed as "I intend to lose weight." When an individual chooses the weight loss as the goal, he/ she could intend to consume 1,500 calories or less very everyday or to run 3 miles every Monday, Wednesday, and Friday. The intentions for implementing actions are characterized as implementation intentions (Bagozzi et al. 2003; Dholakia et al. 2007; Perugini and Bagozzi 2001, 2003).

Similarly, when the reading information is regarded as the chosen goal, the implementation intention is marked as the action toward the chosen goal. In the case of the reading information, the implementation intention could be expressed as "a manager intends to create their own reports" or "a manager intends to request IT professionals to create the reports" (see Fig. 3). Because the later is not included in the scope of this study, we will only investigate the relationship between reading information and creating reports. Therefore, this study argues that reading information is the goal intention and creating reports is the implementation intention.

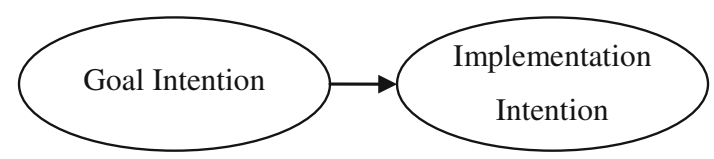

Fig. 2 D\&B model (2002) 


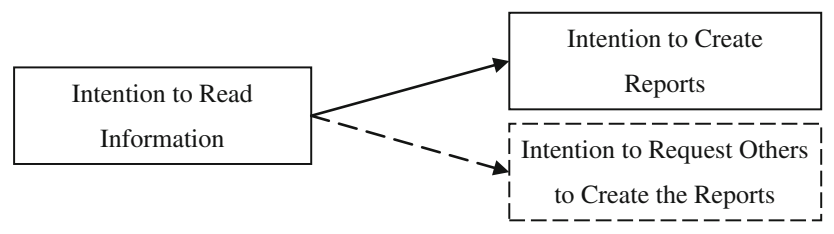

Fig. 3 Implementation intentions of reading information

\section{Research model and hypotheses}

According to the TAM (Davis 1986, 1989), both perceived usefulness and ease of use of systems lead to the behavioral intention. Perceived ease of use of systems also influences their perceived usefulness. BI is designed as a decision support tool for business users to provide friendly interfaces for supporting them to access information (Inmon 2005). Thus, BI is supposed to be useful and easy to read information for managers.

If a manager believes that using BI to read information would enhance his/her job performance or be free of effort, he/she will intend to read information from BI. In addition, the easier it is to use BI to read information, the greater the expected benefits can be derived from BI. If a manager believes that using BI to read information would be free of effort, he/she will believe that using BI would enhance his/ her job performance. This study proposes the following:

H1 PU is positively related to intention to read information.

H2 PEOUR is positively related to intention to read information.

H3 PEOUR is positively related to PU.

Although it has been reported that only limited numbers of managers are willing to create reports, there are no sufficient literatures to support the relationships between the TAM variables and the intention to create reports. Therefore, this study still has to follow the TAM to construct the hypotheses and proposes the following:

H4 PU is positively related to intention to create reports.

H5 PEOUC is positively related to intention to create reports.

\section{H6 PEOUC is positively related to PU.}

For managers, there are basically two ways to get reports, namely by IT professionals or themselves. This first one is the most adopted approach. That is, managers place requests and wait for IT professionals to create the reports for them. However, during the process of creating reports, IT professionals as well as managers have to spend a lot of time on communicating the requirement. The second approach, therefore, though is less adopted before, is a faster approach to get reports. In addition, creating adhoc reports with modern BI does not require writing a single line of code, and data are presented in a user-friendly format, namely star schema (Kimball and Ross 2002). According to the D\&B model, the implementation intention is influenced by the goal intention (Dholakia and Bagozzi 2002). It is reasonable to assume that an aggressive manager may intend to create his/her own reports. For the reason, a manager's perception of ease of reading may also influence his/her that of creating. Therefore, this study proposes the following (Fig. 4):

H7 PEOUR is positively related to PEOUC.

H8 intention to read information is positively related intention to create reports.

\section{Research methodology}

\subsection{Subjects}

Because the subjects of this study are managers, we invited executive master of business administration (EMBA) students to participate in this study. The core courses in EMBA programs are designed to introduce professionals (e.g., managers, executives, and supervisors) to the various areas of business, such as accounting, finance, marketing, human resources, and operational management. Some Taiwanese universities have established cross-strait campuses to provide courses for business managers in mainland China. The formal study population comprised EMBA students from 27 classes in China and Taiwan. The 852 questionnaires were mailed to 410 Chinese and 442 Taiwanese students.

\subsection{Measurement development}

Perceived usefulness, PEOUR, and PEOUC items were adapted from Davis (1989) and Davis et al. (1989). intention to read information and intention to create reports items were adapted from Perugini and Bagozzi (2001). Before conducting the formal survey, we invited $20 \mathrm{BI}$ consultants to participate in a pre-test. After reviewing and filling in the pre-test questionnaire, these consultants provided suggestions related to wording, length, and format of the items in the questionnaire. Based on the results of the pre-test, the final 16 items were developed for the questionnaire (see "Appendix 1"). The English measurement was translated into traditional and simplified Chinese. The back-translation method was applied to ensure consistency between versions (Mullen 1995). All items were measured by a seven-point Likert scale ranging from strongly disagree (1) to strongly agree (7). Table 1 details the operational definitions of five constructs. 
Fig. 4 Research model

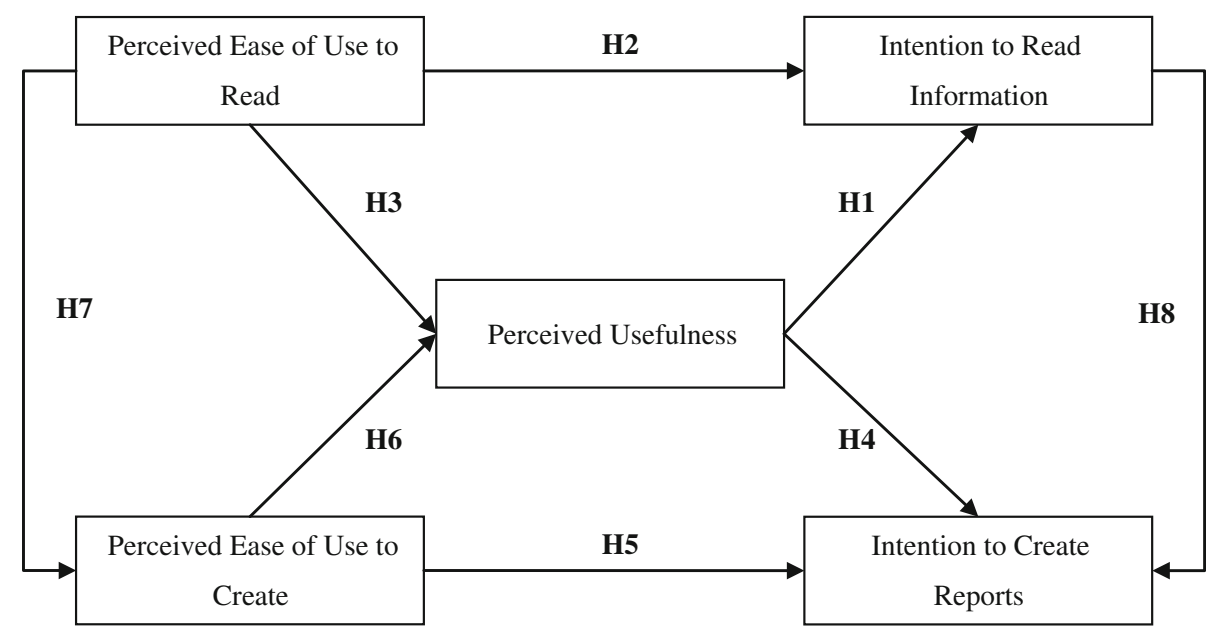

\subsection{Data collection}

The data were gathered during the spring and summer of 2011. Of the 852 questionnaires mailed, 118 and 153 were returned from China and Taiwan, respectively. The total response rate is $31.8 \%$. The percentages of male and female respondents are 80.8 and $19.2 \%$, respectively. The percentage of female respondents in the sample is similar to the percentage of female management positions globally in 2011 , $20 \%$, as reported by the International Business Report (2011). Most respondents' age ranges from 36 to 45 years $(49.1 \%)$. The respondents work in strategy departments $(22.9 \%)$ and in electronic manufacturing industries $(37.6 \%)$. All of the respondents have experience using BI. The 271 respondents' characteristics are presented in "Appendix 2".

\section{Results}

\subsection{Assessment of the measurement model}

This study examines the measurement model by convergent and discriminant validity. The convergent validity of the measurements is assessed using the item reliability, the composite (construct) reliability, and the average variance extracted (AVE) (Fornell and Larcker 1981). The item reliability is assessed using factor loadings. Table 2 shows that the factor loadings of the measures range from 0.75 to
0.89, which exceed the 0.7 loading criterion (Hair et al. 1992). The construct reliability is assessed using Cronbach's $\alpha$. Table 3 shows that the Cronbach's $\alpha$ for the constructs ranges from 0.89 to 0.94 , which exceed the recommended level of 0.7 (Nunnally 1978).

Table 4 shows that the composite reliabilities (CR) for the constructs range from 0.89 to 0.93 , which exceed the recommended value of 0.7 . The AVE for the constructs range from 0.74 to 0.84 , which exceed the recommended value of 0.5 (Fornell and Larcker 1981). In addition, the squared root of the AVE of each construct is larger than its correlations with other constructs. Therefore, the convergent and discriminant validity are confirmed.

The fitness measures for the measurement model are tested by $\chi^{2}$, GFI (goodness-of-fit index), AGFI (adjusted goodness-of-fit index), NFI (normed fit index), and CFI (comparative fit index). The proposed model shows that the $\chi^{2} /$ d.f. is $2.01\left(\chi^{2}=189.4\right.$; d.f. $\left.=94\right)$, which is less than 5 (Kettinger and Lee 1994). The GFI and AGFI are 0.92 and 0.89 , which are greater than the recommended value of 0.8 (Scott 1995). The NFI and CFI are 0.95 and 0.98, which are higher than the recommended value of 0.9 (Bentler and Bonnett 1980).

\subsection{Assessment of the structural model}

This study examines the structural equation model (SEM) by testing the hypothesized relationships between five

Table 1 Definition of constructs

\begin{tabular}{lll}
\hline Construct & Operational definitions & Source \\
\hline Perceived Usefulness (PU) & The belief that using BI would enhance job performance & Davis (1989) \\
Perceived Ease of Use to Read (PEOUR) & $\begin{array}{l}\text { The belief that using BI to read information from reports } \\
\text { would be free of effort }\end{array}$ & Davis (1989) \\
Perceived Ease of Use to Create (PEOUC) & $\begin{array}{l}\text { The belief that using BI to create reports would be free of effort } \\
\text { Intention to Read Information (IR) }\end{array}$ & $\begin{array}{l}\text { The strength of one's willingness to read information from reports } \\
\text { Intention to Create Reports (IC) }\end{array}$ \\
\hline
\end{tabular}


Table 2 Results of confirmatory factor analysis

\begin{tabular}{llllll}
\hline & PU & PEOUR & PEOUC & IR & IC \\
\hline PU1 & $\mathbf{0 . 8 3}$ & 0.13 & 0.09 & 0.31 & 0.12 \\
PU2 & $\mathbf{0 . 8 0}$ & 0.15 & 0.08 & 0.28 & 0.16 \\
PU3 & $\mathbf{0 . 8 6}$ & 0.07 & 0.16 & 0.18 & 0.15 \\
PU4 & $\mathbf{0 . 8 4}$ & 0.16 & 0.14 & 0.19 & 0.19 \\
PEOUR1 & 0.13 & $\mathbf{0 . 8 2}$ & 0.33 & 0.16 & 0.20 \\
PEOUR2 & 0.24 & $\mathbf{0 . 7 7}$ & 0.34 & 0.17 & 0.24 \\
PEOUR3 & 0.14 & $\mathbf{0 . 7 9}$ & 0.38 & 0.11 & 0.25 \\
PEOUC1 & 0.11 & 0.29 & $\mathbf{0 . 8 9}$ & 0.07 & 0.16 \\
PEOUC2 & 0.19 & 0.33 & $\mathbf{0 . 7 8}$ & 0.19 & 0.23 \\
PEOUC3 & 0.14 & 0.31 & $\mathbf{0 . 8 5}$ & 0.16 & 0.19 \\
IR1 & 0.36 & 0.10 & 0.18 & $\mathbf{0 . 7 7}$ & 0.22 \\
IR2 & 0.36 & 0.20 & 0.11 & $\mathbf{0 . 7 8}$ & 0.29 \\
IR3 & 0.33 & 0.15 & 0.15 & $\mathbf{0 . 7 5}$ & 0.27 \\
IC1 & 0.24 & 0.12 & 0.21 & 0.26 & $\mathbf{0 . 8 5}$ \\
IC2 & 0.21 & 0.28 & 0.21 & 0.21 & $\mathbf{0 . 8 5}$ \\
IC3 & 0.17 & 0.30 & 0.20 & 0.29 & $\mathbf{0 . 8 0}$ \\
\hline Bold & &
\end{tabular}

Bold values indicate loading of the measures

Table 3 Reliability of constructs

\begin{tabular}{lllll}
\hline Construct & Items & Mean & SD & Cronbach's $\alpha$ \\
\hline PU & 4 & 5.75 & 0.81 & 0.92 \\
PEOUR & 3 & 5.12 & 1.08 & 0.92 \\
PEOUC & 3 & 5.04 & 1.08 & 0.93 \\
IR & 3 & 5.64 & 0.91 & 0.89 \\
IC & 3 & 5.36 & 1.09 & 0.94 \\
\hline
\end{tabular}

Table 4 Inter-construct correlations

\begin{tabular}{llllllll}
\hline & CR & AVE & PU & PEOUR & PEOUC & IR & IC \\
\hline PU & 0.93 & 0.74 & $\mathbf{0 . 8 6}$ & & & & \\
PEOUR & 0.89 & 0.79 & 0.47 & $\mathbf{0 . 8 9}$ & & & \\
PEOUC & 0.91 & 0.82 & 0.40 & 0.77 & $\mathbf{0 . 9 1}$ & & \\
IR & 0.90 & 0.75 & 0.74 & 0.53 & 0.46 & $\mathbf{0 . 8 7}$ & \\
IC & 0.92 & 0.84 & 0.52 & 0.64 & 0.55 & 0.67 & $\mathbf{0 . 9 2}$ \\
\hline
\end{tabular}

Bold values indicate square roots of the average variance

variables (see Fig. 5). The results show that PEOUC $(\beta=0.324, p<0.001)$ and intention to read information ( $\beta=0.529, p<0.001)$ have a significant effect on intention to create reports, supporting $\mathrm{H} 5$ and $\mathrm{H} 8$. The model accounts for $54 \%$ of the variance in intention to create reports. Contrary to expectations, PU has no direct influence on intention to create reports $(\beta=0.000, p>0.05)$, and $\mathrm{H} 4$ is not supported. In addition, the results show that PU $(\beta=0.617, p<0.001)$ and PEOUR $(\beta=0.252$, $p<0.001)$ have significant effects on intention to read information, supporting $\mathrm{H} 1$ and $\mathrm{H} 2$. Together, the two paths accounts for $59 \%$ in intention to read information. Unexpectedly, only PEOUR significantly affects PU ( $\beta=0.389, p<0.001)$, providing support for H3. PEOUC has no direct influence on PU ( $\beta=0.101, p>0.05)$, and H6 is not supported. The variable explains $22 \%$ of the variance in PU. PEOUR significantly affects PEOUC ( $\beta=0.780, p<0.001)$, and $\mathrm{H} 7$ is supported. The variable explains $61 \%$ of the variance in PEOUC.

\section{Discussion}

In this study, the relationships involving intention to read information are consistent with the traditional TAM. In the analysis, we have found significant support that PU affects intention to read information. Similarly, PEOUR significantly affects both PU and intention to read information. Briefly, a manager's perception of ease of use indirectly leads to use BI through the usefulness of BI. The above direct effects are at 0.001 levels and thus confirm all earlier cited studies of the TAM (Davis 1989; Davis et al. 1989; Taylor and Todd 1995; Venkatesh and Davis 2000).

This study renders an interesting result for PEOUC and intention to create reports. The two constructs are separated from the original core constructs of the TAM. The results show that only PEOUC significantly affects intention to create reports. However, PEOUC is not found to significantly influence PU. The means of PU and PEOUC are 5.75 and 5.04, respectively. Therefore, it is inferred that a good experience with the reading interface, not the creating interface, leads managers to understand that $\mathrm{BI}$ is important to their jobs. Another possible source is that the usefulness of $\mathrm{BI}$ might be derived from the news or word of mouth. One of the BI consultants expressed that though the creating interface of BI is easy to use for managers, creating reports might require extended knowledge, stating that:

Most managers can read default reports in BI or reports created by IT professionals. The reason for this phenomenon may be that the reading interface (e.g., opening files) is easy to use for managers. However, creating reports requires some extended knowledge of the meaning of attributes in related star schema and how the attributes are cleaned and derived from source data. In a sense, managers need to understand the metadata of attributes to create a report. However, most implementation projects do not pay much attention to maintaining metadata.

PU is not found to significantly influence intention to create reports. The mean of intention to create reports $($ mean $=5.36)$ is lower than that of PU (mean $=5.75)$. At 
Fig. 5 Results of structural modeling analysis

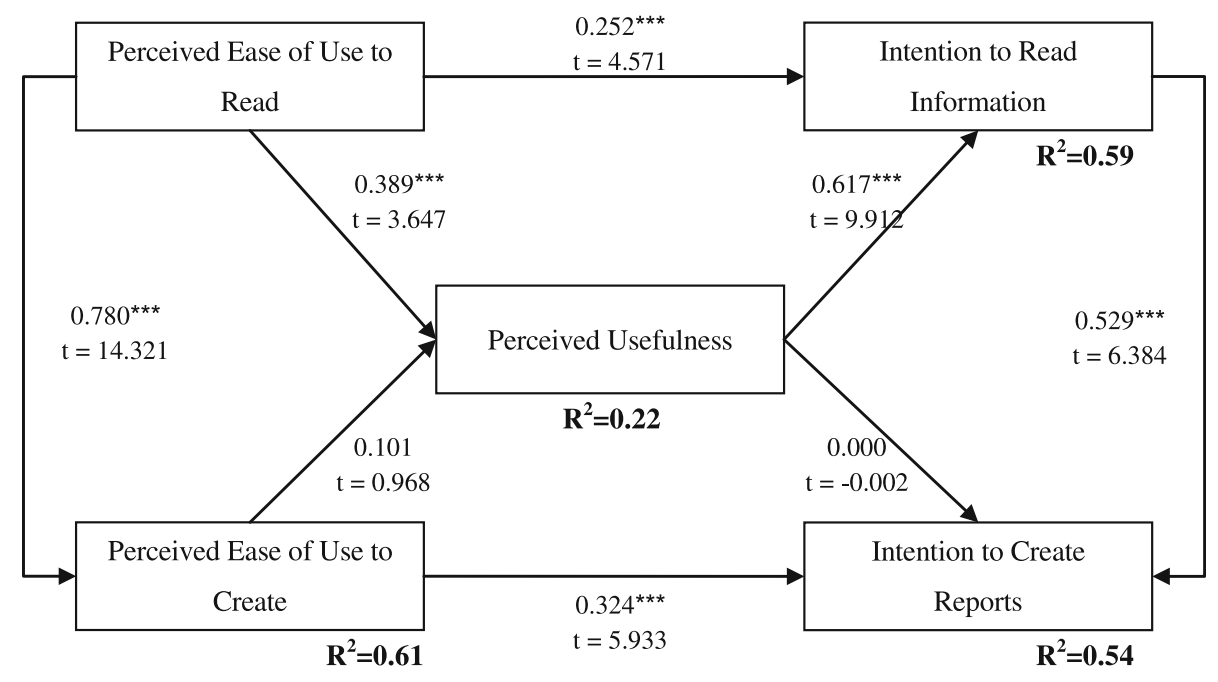

first glance, this finding might appear to be odd. However, it is reasonable. As the SAP reports (2008), managers are accustomed to requesting IT professionals to create the reports for their decision-making process. Pijpers et al. (2001) also posit that creating reports is not viewed as a part of a manager's daily routine or managerial tasks. Even if managers know BI is useful, they spend as little time as possible creating reports. A BI consultant expressed that managers' habits might influence their willingness to create reports, stating that:

Generally, managers regard BI reports as being useful in their decision making. However, most managers tend to request that IT professionals create reports based on the notion that managers are always busy with other tasks; thus, delegating these jobs to others can save time for managers. In addition, it is easy for managers to verbally propose the contents of a report that they need.

As expected, the significant positive effect of PEOUR on PEOUC is validated. This study confirms that PEOUR indirectly affects intention to create reports through PEOUC. Furthermore, intention to read information also significantly affects intention to create reports. The result is in line with the D\&B model, which argues that the goal intention leads to the implementation intention (Bagozzi et al. 2003; Dholakia and Bagozzi 2002; Dholakia et al. 2007; Perugini and Bagozzi 2001, 2003).

\section{Implications for research and practice}

\subsection{Implications for research}

The bulk of existing studies on decision support tools have assumed that system usage intention can be conceptualized as a single construct. This study provides the first empirical evidence to show that the intention to use BI should be split into two different constructs, namely reading information and creating reports. In addition, the antecedents of intention to read information are in line with the TAM, while those of intention to create reports are not. In addition, the relationship between the intention to read information and to create reports is linked using the D\&B model. From a theoretical perspective, this study contributes to the research literatures in three ways.

First, all the relationships posited by the TAM have been supported in the context of reading information. That is, PU and PEOUR have a positive effect on intention to read information and PEOUR has a positive effect on PU. The results show that the perception of usefulness of BI has a stronger effect than that of ease of reading. The finding is consistent with previous studies that discover PU is a critical determinant of the intention to use decision support tools, such as data warehouse (Hong et al. 2006), DSS (Djamasbi et al. 2010), and EIS (Pijpers et al. 2001).

Second, the results show that PEOUC has an influence on intention to create reports, while PU has no significant effect on the same intention. Also, PEOUC does not significantly affect PU. Since many managers still delegate the tasks of creating reports to IT professionals, they do not want do "other jobs," not matter how easy it is. Such working habits influence their intention to create reports. The working habits may be changed through peer influence and social norm derived from organizational behavior theory. These variables that come from peers or other members from an individual's social network could be highly related to an individual's decision to adopt IT (Burt 1997; Granovetter 1973). The insignificant relationship between PEOUC and PU implies that user interfaces are not the only obstacles that hinder 
managers to gain benefit from BI. In this case, this study believes that many data are one of the factors. Therefore, in the era of big data, the factors affecting usage intention may also include the easily locating the needed attributes.

Third, intention to read information significantly affects intention to create reports. The result shows that managers who intend to read information are willing to create their own reports. When today's IS theories and models (e.g., the Theory of Reasoned Action, the Theory of Planned Behavior, and the TAM) only focus on a single usage intention, namely the implementation intention (Bagozzi et al. 2003), this study contributes to the literatures by showing that there are more than one usage intention that should be considered in modern decision support tools, and these intentions are related to each other.

\subsection{Implications for practice}

Based on the findings, intention to read information is confirmed as the determinant of intention to create reports. Because a manager's intention to read information strongly determines his/her willingness to create the reports, we suggest that the intention to read information should be enhanced. According to organizational behavioral research (Robbins and Judge 2007), individual behavior is driven by the benefits of the action. That is, organizational rewards can motivate an individual to perform certain behaviors. Therefore, organizations use rewards to encourage managers to read information from reports in their decision making. We also suggest that organizations can establish a norm for using information among managers. When managers know that the organization expects them to use information in their decision making and sees colleagues doing so, they will be forced to read information from reports.

The findings also point out that the creating interface is more difficult to conquer than the reading interface. There are two reasons. First, the interface to manage metadata must be refined. Often, managers cannot understand the meaning of many attributes in BI and thus find them difficult to use. Second, there are too many attributes and tables listed in BI, which make the task of choosing the correct attributes to form a meaningful report more daunting. Most BI provides a metadata management interface. However, the functions are not always carefully utilized in BI implementation projects, and some of the functions are not clearly explained to users. Therefore, we suggest that software companies and consulting firms better organize metadata and better train managers in their use.
We also encourage software companies and consulting firms that use KPI ontology or a conceptual hierarchy to organize attributes used in BI to help managers understand what attributes might be needed in their reports. A knowledge management system to help managers communicate and learn from one another might also be necessary.

\section{Conclusion and limitations}

BI is widely used in organizations to support managers to make decisions. While the behavioral intentions of DSS and EIS usage have been extensively studied, there are few BI studies. To the best of our knowledge, this study is the first to distinguish the intention to BI into two different constructs, namely intention to read information and intention to create reports. The latter is influenced by the former. Thus, increasing a manager's intention to read information would improve his/her willingness to create reports. Another major finding is that PEOU should also be divided into PEOUR (for reading information) and PEOUC (for creating reports). Past studies have demonstrated the effectiveness of PEOU in explaining the behavioral intention. Our study also finds that both PEOUR and PEOUC significantly affect the intention to read information and the intention to create reports, respectively. Thus, increasing a manager's perception of ease of use would increase his/her intention to use BI. Our data show that PU is useful in explaining PEOUR and intention to read information, but has no influence on PEOUC and intention to create reports. Though PU cannot directly affect intention to create reports, it still can affect intention to create reports through intention to read information. Thus, we suggest that the usefulness of BI should be emphasized in environments where BI is used.

The application of this conclusion is restricted in several ways. First, a bias of self-report scales might exist in this study. Second, because data were cross-sectional and not longitudinal, the posited casual relationships might only be inferred rather than proven. Third, though it has been demonstrated that the behavioral intention leads to actual use behavior, we stop at the intention to create reports. Finally, it might be worthwhile to integrate additional models into our research model, which employs only the TAM and D\&B models.

Open Access This article is distributed under the terms of the Creative Commons Attribution License which permits any use, distribution, and reproduction in any medium, provided the original author(s) and the source are credited. 


\section{Appendix 1: Measurement items of constructs}

\begin{tabular}{|c|c|c|}
\hline Construct & Measurement items & Source \\
\hline Perceived usefulness & $\begin{array}{l}\text { 1. Using BI improves my decision-making performance } \\
\text { 2. Using BI enhances my effectiveness in the decision making } \\
\text { 3. Using BI makes it easier to make my decisions } \\
\text { 4. Overall, I find BI useful to my decision making }\end{array}$ & $\begin{array}{l}\text { Davis (1989), Davis et al. } \\
\text { (1989) }\end{array}$ \\
\hline $\begin{array}{l}\text { Perceived ease of use to } \\
\text { read }\end{array}$ & $\begin{array}{l}\text { 1. Learning to use BI to read information from reports is easy for me } \\
\text { 2. It would be easy for me to become skillful at using BI to read information from } \\
\text { reports } \\
\text { 3. I would find BI easy to use to read information from reports }\end{array}$ & $\begin{array}{l}\text { Davis (1989), Davis et al. } \\
\text { (1989) }\end{array}$ \\
\hline $\begin{array}{l}\text { Perceived ease of use to } \\
\text { create }\end{array}$ & $\begin{array}{l}\text { 1. Learning to use BI to create reports is easy for me } \\
\text { 2. It would be easy for me to become skillful at using BI to create reports } \\
\text { 3. I would find BI easy to use to create reports }\end{array}$ & $\begin{array}{l}\text { Davis (1989), Davis et al. } \\
\text { (1989) }\end{array}$ \\
\hline $\begin{array}{l}\text { Intention to read } \\
\text { information }\end{array}$ & $\begin{array}{l}\text { 1. I am planning to read information from reports } \\
\text { 2. I intend to read information from reports } \\
\text { 3. I will expend effort to read information from reports }\end{array}$ & Perugini and Bagozzi (2001) \\
\hline Intention to create reports & $\begin{array}{l}\text { 1. I am planning to create reports } \\
\text { 2. I intend to create reports } \\
\text { 3. I will expend effort to create reports }\end{array}$ & Perugini and Bagozzi (2001) \\
\hline
\end{tabular}

\section{Appendix 2: Demographic profile}

Location:

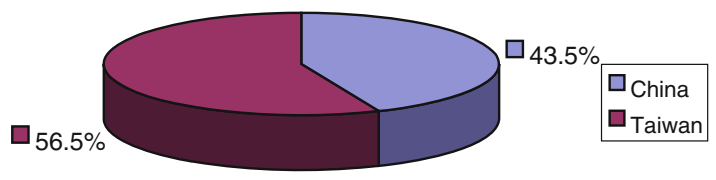

Gender:

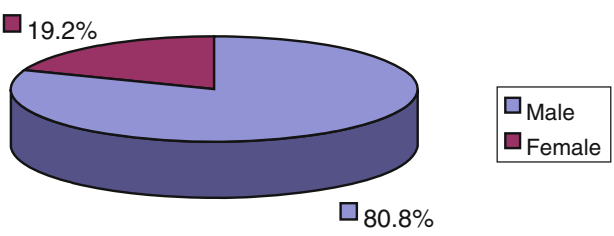

Age:

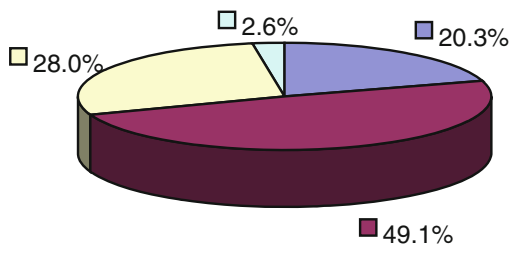


Department:

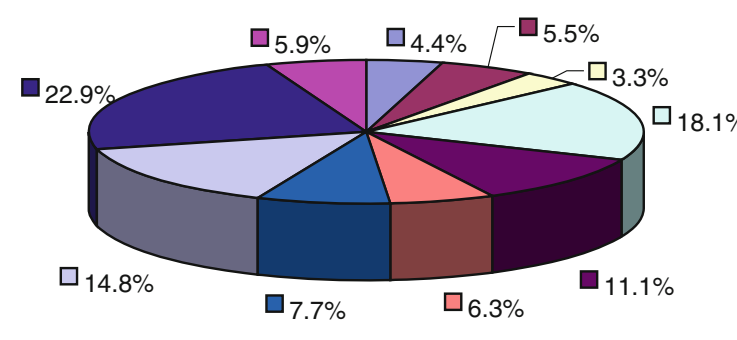

\begin{tabular}{l}
\hline Administration \\
$\square_{\text {Financial accounting }}$ \\
$\square_{\text {Human resources }}$ \\
$\square$ Information technology \\
$\square_{\text {Manufacturing }}$ \\
$\square$ Purchase \\
$\square$ Research and development \\
$\square$ Sales and distribution \\
$\square$ Strategy \\
$\square$ Others
\end{tabular}

Industry type

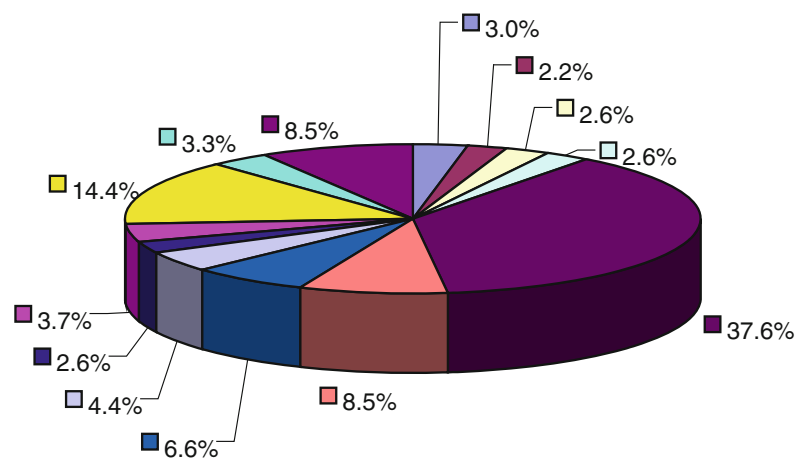

$\square$ Automotive

$\square$ Chemical and energy

$\square$ Construction

$\square$ Electricity and gas

Electronic manufacturing

$\square$ Finance and insurance

$\square$ Information service

$\square$ Logistic and transportation

$\square$ Machinery

$\square$ Medical

$\square$ Semiconductor

$\square$ Telecom

$\square$ Others

Experiences in BI:

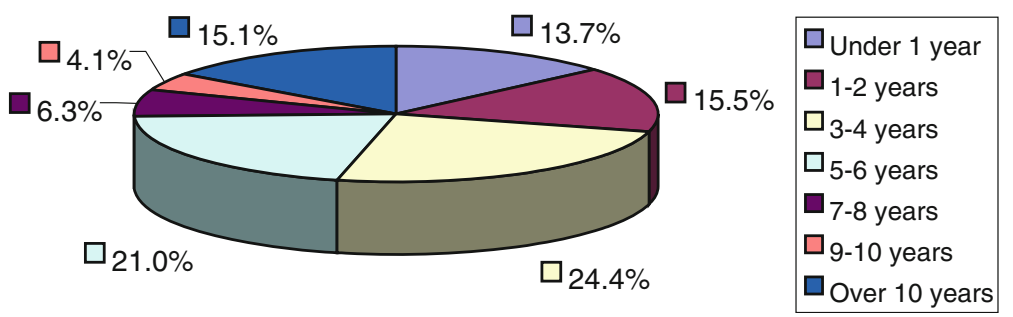


Time in reading information per month:
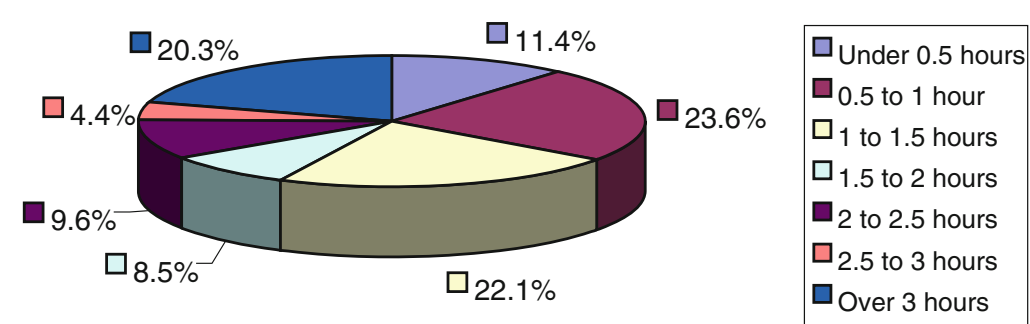

Time in creating reports per month:
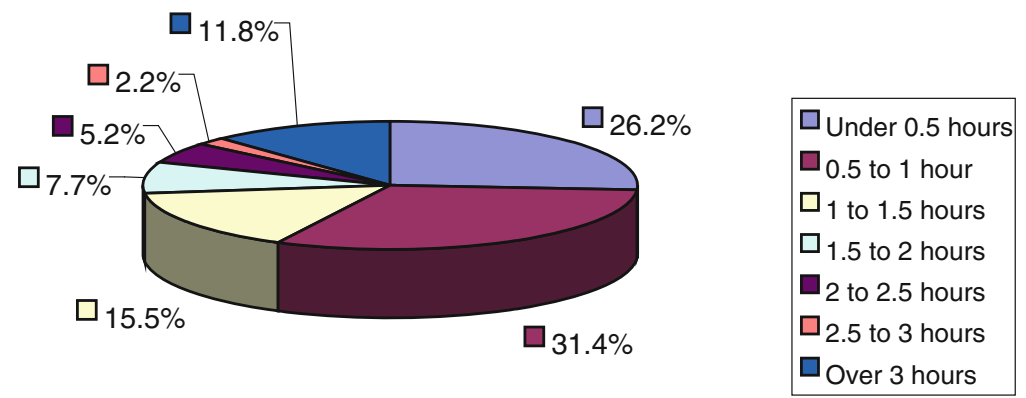

\section{References}

Amoako-Gyampah K (2007) Perceived usefulness, user involvement and behavioral intention an empirical study of ERP implementation. Comput Hum Behav 23(3):1232-1248

Amoako-Gyampah K, Salam AF (2004) An extension of the technology acceptance model in an ERP implementation environment. Inf Manag 41(6):731-745

Bagozzi RP, Dholakia UM, Basuroy S (2003) How effortful decisions get enacted the motivating role of decision processes, desires, and anticipated emotions. J Behav Decis Mak 16(4):273-295

Beach LR (1990) Image theory: decision making in personal and organizational contexts. Wiley, Chichester

Benbasat I, Barki H (2007) Quo vadis, TAM? J Assoc Inf Syst 8(4):211-218

Bentler P, Bonnett D (1980) Significance tests and goodness-of-fit in the analysis of covariance structures. Psychol Bull 88(3): 588-606

Bueno S, Salmeron JL (2008) TAM-based success modeling in ERP. Interact Comput 20(6):515-523

Burt RS (1997) The contingent value of social capital. Adm Sci Q 42(2):339-365

Chan SH (2009) The roles of user motivation to perform a task and decision support system (DSS) effectiveness and efficiency in DSS use. Comput Hum Behav 25(1):217-228

Chong AYL, Ooi KB, Lin B, Bao H (2012) An empirical analysis of the determinants of $3 \mathrm{G}$ adoption in China. Comput Hum Behav 28(2):360-369

Davis FD (1986) A technology acceptance model for empirically testing new end-user information systems: theory and results. Dissertation, Sloan School of Management, Massachusetts Institute of Technology
Davis FD (1989) Perceived usefulness, perceived ease of use, and user acceptance of information technology. MIS Q 13(3): 319-340

Davis FD, Bagozzi RP, Warshaw PR (1989) User acceptance of computer technology: a comparison of two theoretical models. Manag Sci 35(8):982-1003

Devaraj S, Easley RF, Crant JM (2008) How does personality matter? Relating the five-factor model to technology acceptance and use. Inf Syst Res 19(1):93-105

Dholakia UM, Bagozzi RP (2002) Mustering motivation to enact decisions: how decision process characteristics influence goal realization. J Behav Decis Mak 15(3):167-188

Dholakia UM, Bagozzi RP, Gopinath M (2007) How formulating implementation plans and remembering past actions facilitate the enactment of effortful decisions. J Behav Decis Mak 20(4):343-364

Djamasbi S, Loiacono ET (2008) Do men and women use feedback provided by their decision support systems (DSS) differently? Decis Support Syst 44(4):854-869

Djamasbi S, Strong DM, Dishaw M (2010) Affect and acceptance: examining the effects of positive mood on the technology acceptance model. Decis Support Syst 48(2):383-394

Elbeltagi I, Neil M, Glenn H (2005) Evaluating the factors affecting DSS usage by senior managers in local authorities in Egypt. J Glob Inf Manag 13(2):42-65

Fishbein M, Ajzen I (1975) Belief, attitude, intentions, and behavior: an introduction to theory and research. Addison-Wesley, Boston

Fornell C, Larcker DF (1981) Evaluating structural equations with unobservable variables and measurement error. J Mark Res 18(1):39-50

Gantz JF, Chute C, Manfrediz A, Minton S, Reinsel D, Schlichting W, Toncheva A (2008) The diverse and exploding digital universe: 
An updated forecast of worldwide information growth through 2011. EMC. http://www.emc.com/collateral/analyst-reports/diverseexploding-digital-universe.pdf. Accessed 15 Dec 2012

Gartner (2012) Gartner says worldwide business intelligence, analytics and performance management software market surpassed the $\$ 12$ billion mark in 2011. Gartner Newsroom. http://www. gartner.com/it/page.jsp?id=1971516. Accessed 15 Dec 2012

Gefen D, Karahanna E, Straub DW (2003) Trust and TAM in online shopping: an integrated model. MIS Q 27(1):51-90

Gollwitzer PM (1996) The volitional benefits of planning. In: Gollwitzer PM, Bargh JA (eds) The psychology of action: linking cognition and motivation to behaviour. The Guilford Press, New York

Granovetter MS (1973) The strength of weak ties. Am J Sociol 78(6):1360-1380

Grant Thornton (2011) Proportion of women in senior management falls to 2004 levels. International Business Report, Grant Thornton. http://www.internationalbusinessreport.com/Press-room/ 2011/women_in-senior_management.asp. Accessed 15 Dec 2012

Hair JF, Anderson RE, Tatham RL, Black WC (1992) Multivariate data analysis with readings. MacMillan, New York

Hart M, Porter G (2004) The impact of cognitive and other factors on the perceived usefulness of OLAP. J Comput Inf Syst 47-56

Heckhausen H, Kuhl J (1985) From wishes to action: the dead ends and short cuts on the long way to action. In: Frese M, Sabini J (eds) Goal directed behavior: the concept of action in psychology. Erlbaum, Hillsdale, pp 134-159

Hester AJ (2011) A comparative analysis of the usage and infusion of wiki and non-wiki-based knowledge management systems. Inf Technol Manag 12(4):335-355

Hong S, Katerattanakul P, Hong SK, Cao Q (2006) Usage and perceived impact of data warehouses: a study in Korean financial companies. Int J Inf Technol Decis Mak 5(2):297-315

Hsu CL, Lin JCC (2008) Acceptance of blog usage: the roles of technology acceptance, social influence and knowledge sharing motivation. Inf Manag 45(1):65-74

IBM (2012) What is big data? Bringing big data to the enterprise. IBM. http://www-01.ibm.com/software/data/bigdata/. Accessed 15 Dec 2012

Inmon WH (2005) Building the data warehouse, 4th edn. John Wiley \& Sons, New York

Jourdan Z, Rainer RK, Marshall TE (2008) Business intelligence: an analysis of the literature. Inf Syst Manag 25(2):121-131

Kettinger WJ, Lee CC (1994) Perceived service quality and user satisfaction with the information services function. Decis Sci 25(5-6):737-763

Kimball R, Ross M (2002) The data warehouse toolkit: the complete guide to dimensional modeling, 2nd edn. Wiley, New York

Kuo RZ, Lee GG (2011) Knowledge management system adoption: exploring the effects of empowering leadership, task-technology fit and compatibility. Behav Inf Technol 30(1):113-129

Lederer AL, Maupin DJ, Sena MP, Zhuang Y (2000) The technology acceptance model and the World Wide Web. Decis Support Syst 29(3):269-282

Mayer JH, Winter R, Mohr T (2011) Utilizing user-group characteristics to improve acceptance of management support systemsState of the art and six design guidelines. Lect Notes Comput Sci 6629:291-305

Moon JW, Kim YG (2001) Extending the TAM for a World-WideWeb context. Inf Manag 38(4):217-230
Mullen MR (1995) Diagnosing measurement equivalence in crossnational research. J Int Bus Stud 26(3):573-596

Nunnally JC (1978) Psychometric methods, 2nd edn. McGraw-Hill, New York

Perugini M, Bagozzi RP (2001) The role of desires and anticipated emotions in goal-directed behaviours: broadening and deepening the theory of planned behaviour. Br J Soc Psychol 40(1):79-98

Perugini M, Bagozzi RP (2003) The distinction between desires and intentions. Eur J Soc Psychol 34(1):69-84

Perugini M, Conner M (2000) Predicting and understanding behavioral volitions: the interplay between goals and behaviors. Eur J Soc Psychol 30(5):705-731

Pijpers GGM, Bemelmans TMA, Heemstra FJ, Montfort KAGM (2001) Senior executives' use of information technology. Inf Softw Technol 43(15):959-971

Pirttimäki V, Hannula M (2003) Process models of business intelligence. Frontiers of E-Business Research 250-260

Pommeranz A, Wiggers P, Brinkman WP, Jonker CM (2011) Social acceptance of negotiation support systems: scenario-based exploration with focus groups and online survey. Cogn Technol Work 14(4):299-317

Rathnam S, Mannino MV (1995) Tools for building the humancomputer interface of a decision support system. Decis Support Syst 13(1):35-59

Robbins SP, Judge TA (2007) Organizational behavior, 13th edn. Prentice Hall, New Jersey

Sankar CS, Ford FN, Bauer M (1995) A DSS user interface model to provide consistency and adaptability. Decis Support Syst 13(1):93-104

SAP AG (2008) SAP ERP-integration of business process participant handbook

Schilke O, Wirtz BW (2012) Consumer acceptance of service bundles: an empirical investigation in the context of broadband triple play. Inf Manag 49(2):81-88

Scott JE (1995) The measurement of information systems effectiveness: evaluating a measuring instrument. Data Base Adv 26(1):43-61

Scott JE, Walczak S (2009) Cognitive engagement with a multimedia ERP training tool: assessing computer self-efficacy and technology acceptance. Inf Manag 46(4):221-232

Speier C, Morris MG (2003) The influence of query interface design on decision-making performance. MIS Q 27(3):397-423

Svenson O (1997) Differentiation and consolidation theory. In: Flin R, Salas E, Strub M, Martin L (eds) Decision making under stress: emerging theories and applications. Aldershot, UK, pp 301-314

Taylor S, Todd PA (1995) Understanding information technology usage: a test of competing models. Inf Syst Res 6(2):144-176

Venkatesh V, Davis FD (2000) A theoretical extension of the technology acceptance model: four longitudinal field studies. Manag Sci 46(2):186-204

Vijayasarathy LR (2004) Predicting consumer intentions to use online shopping: the case for an augmented technology acceptance model. Inf Manag 41(6):747-762

Watson H, Ariyachandra T, Matyska R (2001) Data warehousing stages of growth. Inf Syst Manag 18(3):42-50

Yates JF (1990) Judgment and decision making. Prentice Hall, New Jersey

Zarmpou T, Saprikis V, Markos A, Vlachopoulou M (2012) Modeling users' acceptance of mobile services. Electron Commer Res 12(2):225-248 